Шаповалова Яна Витальевна

кандидат юридических наук, доцент кафедры общетеоретических правовых дисциплин Северо-Кавказского филиала Российского государственного университета правосудия

\section{НЕКОТОРЫЕ ПРОБЛЕМЫ МЕТОДОЛОГИИ ПОСТРОЕНИЯ КОНЦЕПЦИИ ИНТЕГРАТИВНОГО ПРАВОПОНИМАНИЯ И ЕЕ РАЗВИТИЕ В СОВРЕМЕННОЙ ТЕОРИИ ПРАВА}

\begin{abstract}
Аннотация:
В статье исследуются предпосылки формирования новых концепций правопонимания в условиях методологического кризиса современной юридической науки. Теоретическая дискуссия о понимании сущности права ведется не одно столетие, однако современная правовая действительность ставит перед наукой задачу переосмысления методологического подхода к категории «право». В настоящее время российские теоретики права разрабатывают несколько концепций правопонимания, которые объединяют под одним обобщающим понятием «интегративные концепции права», однако критериев для отнесения их к интегративному типу правопонимания в юриспруденции пока не выработано. Аєтор, анализируя различные подходы по вопросу развития интегративной школы права, приходит к выводу, что оно видится в устоявшемся понятии о нормативности права, но при допустимости судебного правотворчества. При этом право рассматривается как общесоциальный регулятор, а естественные права личности позиционируются как ориентир для любого правотворчества. Необходимо также учесть, что предполагаемая универсальность концепции интегративного понимания права основана на текущем состоянии развития права в конкретный исторический момент и должна отражать современное состояние социальных и политических процессов в обществе.
\end{abstract}

Ключевые слова:

правопонимание, типология правопонимания, сущность права, юридическая наука, интегративные концепции правопонимания, методология юридической науки, понятие права, юридический позитивизм, естественно-правовая школа права, нормативность права.

\section{Shapovalova Yana Vitalyevna}

PhD in Law, Associate Professor, General Theoretic Legal Subjects Department North Caucasus branch of Russian University of Justice

\section{SEVERAL METHODOLOGICAL ISSUES OF ELABORATING THE CONCEPT OF INTEGRATIVE LEGAL THINKING AND ITS DEVELOPMENT IN THE MODERN THEORY OF LAW}

\begin{abstract}
Summary
The paper reviews the prerequisites for the creation of new concepts of legal thinking in terms of the methodological crisis of the modern legal science. The essence of law has been theoretically discussed for centuries. However, the legal science seeks to rethink the methodological approach to the category of law due to the current legal reality. Nowadays, Russian legal theorists develop multiple concepts of legal thinking which are reviewed in the context of an umbrella term of integrative concepts of law; however, there are still no criteria for classifying them as an integrative type of legal thinking in jurisprudence. Based on the analysis of various approaches to the development of the integrative law school, the author concludes that the concept can be elaborated in the well-established notion of legal standards while judicial lawmaking is admissible. At the same time, the right is regarded as a general social regulator, and the natural rights of the personality are identified as a guideline for any lawmaking. Consideration should be given to the fact that the supposed universality of the concept of integrative understanding of law is based on the current state of the development of law at a particular period and should reflect the current state of social and political processes in society.
\end{abstract}

Keywords: legal understanding, types of legal understanding, essence of law, legal science, integrative concepts of legal understanding, methods of legal science, concept of law, legal positivism, natural law school, legal standards.

Перед современной юриспруденцией стоит не один спорный, неразрешимый, но теоретически и практически значимый вопрос. К таким глобальным общетеоретическим проблемам относится научная дилемма о понятии и сущности права.

Теоретическая дискуссия о правопонимании ведется на протяжении веков, однако так необходимая теоретикам, практикам и законодателю научная категория «право» и его методологическое определение не сорормированы до сих пор. Западная научная литература отдает предпочтение множественности точек зрения и концепций правопонимания вместо выработки одной методологии или единого определения [1]. Приверженцы такой концепции говорят о необходимости определять право как полисистемное явление, которое в разных общественных сферах проявляется по-разному.

В российской юридической науке осмысление вопросов правопонимания имеет свою специфику, не совпадающую с западной концепцией. Причин здесь несколько. Во-первых, важным фрактором выступают политическая ситуация и государственное строительство России на протяжении 
XX в. Во-вторых, развитие отечественной юридической науки в этот же период условно можно разделить на три этапа: досоветский, советский и постсоветский. При этом каждый из них являлся обособленным, по сути перечеркивающим все предыдущие взгляды и концепции, т. е. правопреемства в теоретической проработке концепции правопонимания фактически не наблюдалось.

В настоящее время российскими теоретиками права предложено несколько интересных концепций правопонимания, которые объединены под одним обобщающим понятием «интегративные концепции права в России»: либертарная концепция права В.С. Нерсесянца, конституционная концепция правопонимания В.А. Четвернина, коммуникативная концепция права А.В. Полякова, диалогическая концепция права И.Л. Честнова и др.

Н.В. Евдеева, исследуя интегративные теории правопонимания, указывает, что «термин "интегративная юриспруденция" получил распространение в России в начале 1990-х гг. Впервые же упоминание об "интегральной юриспруденции" Дж. Холла можно найти в монографии В.А. Туманова "Критика современной буржуазной теории права"» [2, с. 11]. Как отмечает Н.В. Евдеева, в основе появления и разработки теории интегративного понимания права лежат определенные причины: во-первых, кризис юриспруденции; во-вторых, отсутствие четкого определения критериев научной теории; в-третьих, позиции классических школ права утрачивают актуальность в связи с изменением требований правовой действительности [3, с. 3].

Среди основных направлений развития интегративных концепций выдвигается идея о необходимости выработки универсального понятия права на основе целостной теоретической базы, обобщения опыта российской дореволюционной науки и зарубежных доктрин. Касаясь вопроса об устоявшихся или «классических» концепциях правопонимания, ученые-«интегративисты» отмечают, что они не могут в полной мере удовлетворить современные потребности осмысления правовой действительности по ряду причин. Во-первых, все правовые семьи в настоящий момент испытывают влияние расширения источников права и включения в правовые системы ранее нетрадиционных источников права. Во-вторых, меняются социальные функции права, к традиционным - регулятора конфрликтов и стабилизации общественных отношений - добавляются новые, например функция социальной защиты [4, с. 693].

По вопросу о необходимости интеграции разных школ права В.В. Ершов высказал следующую точку зрения: «в связи с теоретической дискуссионностью и практической недостаточностью юридического позитивизма и естественно-правовой доктрины права в современный период следует руководствоваться интегративным правопониманием, суть которого состоит в том, чтобы не противопоставлять различные типы правопонимания, а находить точки их соприкосновения. Полагаю, что современное интегративное правопонимание может основываться на позитивистской, социологической, либеральной и естественно-правовой концепциях права» [5, с. 105].

Однако ученые, стоящие на классических позициях, утверждают, что выдвижение различных концепций правопонимания в действительности имеет больше отрицательных сторон, чем положительных. В том числе отмечается, что это негативно отражается на процессе обучения: «до сих пор не ясно, на основе какой именно концепции права должно строиться преподавание в юридических вузах» [6, с. 344]. Кроме того, противники плюралистичности взглядов о «праве» констатируют, что дуализм правопонимания, противопоставление права закону на практике приводят к еще более серьезным последствиям, нежели теоретические разногласия. Если в юридической науке нет устоявшегося определения права, это не дает четко фрормулировать другие научные категории, взаимосвязанные или производные от понятия «право». В практической деятельности плюрализм правопонимания выражается в столкновении права и закона и приводит к тому, что под сомнением оказываются еще одни базовые категории: «законность» и «правопорядок» [7, с. 15]. Наконец, отсутствие единой позиции по вопросу о том, какие типы понимания права нужно интегрировать, приводит к тому, что любая концепция, относимая ее авторами к интегративной, не будет иметь под собой научно обоснованной базы, а потому будет являться субъективной. Таким образом, не все теоретики права считают возможным и необходимым объединение различных концепций под одну интегративную школу.

Также необходимо отметить, что подавляющее большинство работ как научной, так и учебной направленности не рассматривают интегративное правопонимание как одно из направлений научной мысли, оставаясь на позициях «классических» школ права. Тем самым категории и критерии интегративного понимания права остаются без внимания.

По нашему мнению, если отвергнуть возможность разработки новых концепций правопонимания, наука останется на позициях методологического отрицания правовой действительности и связь между доктриной и реальностью будет сведена к минимуму. Исходя из того что вопрос формирования обновленного теоретического понятия «право» и анализ его сущности являются актуальными в отечественной теории права, исследование в рамках интегративной концепции права, на наш взгляд, должно синтезировать доктрину классических школ права с их обширным накопленным опытом и сформулировать теоретические базовые понятия, отвечающие реалиям 
современности. Полагаем, что интегративная школа права должна сконцентрироваться на фрактически устоявшихся взглядах о нормативности права, но при этом учесть, что не только судебное правотворчество допускается в одной отдельной правовой семье, но уже распространено повсеместно, что естественные права личности - это общесоциальный ориентир для любого правотворца и правоприменителя, что понятие «право» должно рассматриваться как общесоциальный регулятор. В праве должна быть выражена компромиссная воля «правосознательного» населения на основе взаимодействия интересов разных слоев и групп, религий, наций и иных социальных общностей.

Однако здесь следует поставить некоторые ограничения, так как интегративное правопонимание, несмотря на позиционируемую универсальность, будет иметь распространение в рамках континентальной и англосаксонской систем права, иные правовые семьи (восточные, архаичные) она не затронет.

Еще одно важное замечание заключается в том, что «классические» школы права изучают правовые явления, используя традиционные методы познания. Однако сегодня методология исследования права нуждается в дополнении новыми формами и способами познания, которые уже существуют как результат технического прогресса, глобализации и других современных тенденций. Актуальным в связи с этим является вопрос о внедрении новых методов в исследовательскую деятельность в рамках интегративной юриспруденции. Кроме того, сейчас в интегративных концепциях присутствует многообразие всевозможных дефиниций права, это позволяет отразить в понятии права самые важные его стороны и черты, увидеть право не только в статике, но и в динамике.

Тем не менее следует констатировать, как отмечает Р.Р. Палеха, что «отсутствие интегративного терминологического аппарата и четкой идеи объединения влечет множественность интегративных типов понимания права. Наиболее устоявшейся среди ученых является позиция, что под “интегративным типом правопонимания" понимается не “обновленный” или дополненный элементами из других теорий, а принципиально новый тип понимания права, основанный на объединении традиционных вариантов правопонимания с целью выработать более концентрированное определение права» [8].

Подводя итог анализу состояния развития интегративной школы права, необходимо указать, что интегративные концепции понимания права являются одним из направлений правовой мысли в современной России. В работах, посвященных проблематике интегративной юриспруденции, указывается на методологические проблемы в построении новой научной концепции: отсутствуют единство в трактовке термина «интегративное понимание права» и единая терминология внутри интегративной концепции. Кроме того, нет четкого понимания, на какой основе будут интегрироваться классические концепции. Таким образом, научную методологию объединения разных школ права в одну никто не сформулировал. Следствием этого является отсутствие критериев научности теории, в научной среде единство по вопросу совокупности позиций, по которым осуществляется проверка соответствия теорий научному знанию, не достигнуто.

\section{Ссылки:}

1. Тулмин Ст. История, практика и «третий мир» (трудности методологии Лакатоса) // Философия науки в поисках новых путей. Вып. 5. М., 1999. С. 258-280 ; Feyerabend P.K. Against method. Outline of an anarchistic theory of knowledge. L., 1975.

2. Евдеева Н.В. Интегративные теории правопонимания в современной России : автореф. дис. ... канд. юрид. наук. Н. Новгород, 2005. 26 с.

3. Там же. С. 3 .

4. Графский В.Г. Всеобщая история права и государства : учебник для вузов. 2-е изд., перераб. и доп. М., 2007. 752 с.

5. Ершов В.В. Актуальные проблемы экспертной деятельности Общественной палаты Российской Федерации в свете современного правопонимания, правотворчества и правоприменения // Российское правосудие. 2009. № 5. С. 105.

6. История политических и правовых учений : учебник / под ред. О.Э. Лейста. М., 1997.

7. Толстик В.А. От плюрализма правопонимания к борьбе за содержание права // Государство и право. 2004. № 9. C. $14-15$.

8. Палеха Р.Р. Интегративные концепции правопонимания современной российской юридической науки // Вестник Воронежского института МВД России. 2010. № 3. С. 74-79.

\section{References:}

Ershov, VV 2009, 'Current issues of expert activity of the Public Chamber of the Russian Federation in the context of modern legal understanding, lawmaking and law enforcement', Rossiyskoye pravosudiye, no. 5, p. 105, (in Russian).

Evdeeva, NV 2005, Integrative theory of legal understanding in modern Russia, PhD thesis abstract, Nizhny Novgorod, 26 p., (in Russian).

Feyerabend, PK 1975, Against method. Outline of an anarchistic theory of knowledge, London.

Grafsky, VG 2007, World history of law and state, textbook, 2nd ed., Moscow, 752 p., (in Russian).

Leist, OE (ed.) 1997, History of political and legal doctrines, textbook, Moscow, (in Russian).

Palekha, RR 2010, 'Integrative concepts of legal understanding of modern Russian legal science', Vestnik Voronezhskogo instituta MVD Rossii, no. 3, pp. 74-79, (in Russian).

Tolstik, VA 2004, 'From the pluralism of legal understanding to the struggle for the content of law', Gosudarstvo i parvo, no. 9, pp. 14-15, (in Russian).

Tulmin, St 1999, 'History, practice and the "third world" (challenges of methods by Lakatos)', Filosofiya nauki v poiskakh novykh putey, iss. 5, Moscow, pp. 258-280, (in Russian). 